Seminar Nasional Teknologi Informasi dan Kedirgantaraan (SENATIK)

Vol. III, 21 Desember 2017, P-ISSN: 2337-3881, E-ISSN: 2528-1666

DOI: http://dx.doi.org/10.28989/senatik.v3i0.116

\title{
SIMULASI NUMERIK PERSAMAAN ALIRAN FLUIDA TAK MAMPAT MENGGUNAKAN METODE BEDA HINGGA
}

\author{
Endang Mawarsih ${ }^{1}$, EkoPrasetyo Budiana $^{2}$, Deendarlianto ${ }^{3}$, Samsul Kamal $^{4}$, Indarto ${ }^{5}$ \\ ${ }^{1,2}$ Program Studi S-3 TeknikMesin \\ Departemen Teknik Mesin dan Industri \\ Universitas Gadjah Mada \\ Jl. Grafika No. 2 Yogyakarta 55281 \\ 3,4,5 Departemen Teknik Mesin dan Industri, Universitas Gadjah Mada \\ Jl. Grafika No. 2 Yogyakarta 55281 \\ Email : endfamous@yahoo.com
}

\begin{abstract}
Thenumerical simulation of incompressible fluid flow by using a finite difference method. Governing equations used in present paper consist of the continuity equation and the momentum equation for unsteady flow and incompressible fluid. The governing equation is discretized using a finite differenceto implicit method on the staggered grid. Discretization of time derivative is approached by the Euler method and the space derivative is approximated by a different method. Thegoverning equation solving procedure using the pressure correction scheme. Comparison the result calculation of velocity value $u$ at $x=0.5$ with the result of calculation from the literature shows good suitability. Finite different methods on the staggered grid can solve the problem of incompressible fluid flow to the Reynolds number at $10^{4}$.
\end{abstract}

Keyword: finite difference method, staggered grid, pressure correction.

1. Pendahuluan

Computational Fluid Dynamic (CFD) merupakan metode untuk memprediksi aliran fluida, perpindahan kalor dan berbagai fenomena lainnya. Persamaan atur untuk menyelesaikan persoalan aliran fluida terdiri dari persamaan kekekalan massa, momentum dan energi (Tuakia, 2008). Pengkajian oleh Ghia ,(1982) tentang formulasi kecepatan stream-function 2-D persamaan Navier-Stokes tak mampat digunakan untuk meneliti keefektifan metode multi grid implicit dalam penyelesaian perhitungan aliran dengan Reynolds tinggi. Model persoalan menggunakan aliran yang digerakkan dalam persegi berongga dengan bilangan Renolds tinggi yaitu $R e=10.000$ dan grid $257 \times 257$. Hasil diperoleh adalah pada $\mathrm{Re}=1000$ dan grid 129x129 waktu dibutuhkan 1.5 menit. Sedangkan Er Turk (2005),menggunakan grid 601x601 dengan bilangan Reynolds $\leq 21000$.
Penelitian Marchi (2009), pemodelan numeric pada persamaan Navier-Stokes yang didasari metode finite volume. Diskritisasi menggunakan $1024 \times 1024$ grid dengan bilangan Reynolds $\leq$ $0,01,10,100,400$ dan 1000 . Proses iterative diulang hingga penyelasaian menghasilkan error. Penelitian tentang aliranlid-driven cavity yang dilakukan oleh Tamer,(2017) digunakan untuk validasi kode CFD. Masalahnya diselesaikan dengan menggunakan Graphical Processing Unit (GPU) yang dipercepat kode in-house. Padapenelitian ini, model persamaan NavierStokes tunak, menggunakan Metode Volume Hingga (FVM) dalam formulasi variabel primitif.Studi tentang aliran tunak tak mampat pada lid-driven cavity 2D untuk 100 $<\operatorname{Re}<5000$ menggunakan grid kolokasi 1301x1301 bersama-sama dengan uniform terstruktur. Detil urutan kedua hasil spasial akurat diverifikasi dandisajikan dalam bentuk tabulasi. 
Pada penelitian ini pendekatan persamaan atur aliran fluida tak mampat menggunakan metode beda hingga implicit akan menghasilkan persamaan matriks tridiagonal (three-diagonal matrix equation). Persamaan tersebut diselesaikan dengan menggunakan algoritma Thomas. Keunggulan dari metode implicit yaitu memiliki kestabilan tanpa syarat. Permasalahan penting pada penyelesaian persamaan Navier-Stoke tak mampat yaitu ketika tekanan terhubung secara implicit pada daerah kecepatan dalam persamaan kontinyuitas. Pengembangan skema implisi tterpisah diterapkan pada aliran tak tunak lid-driven cavity. Ditunjukkan bahwa skema Staggered grid untuk aliran tak tunak tak mampat menghasilkan solusi dengan tingkat konvergensi tinggi sesuai skema implicit sepenuhnya melalui diskretisasi spatial yang runtut .

2. Domain Komputasi Dan Syarat Batas

Domain persoalan merupakan kotak persegi berisi udara. Konfigurasi persoalan dan kondisi batas dinyatakan dengan persamaan untuk dinding sisi kanan kiri dan bawah $\mathrm{u}=\mathrm{v}=0$ dan dinding atas $\mathrm{u}=1, \mathrm{v}=0$.

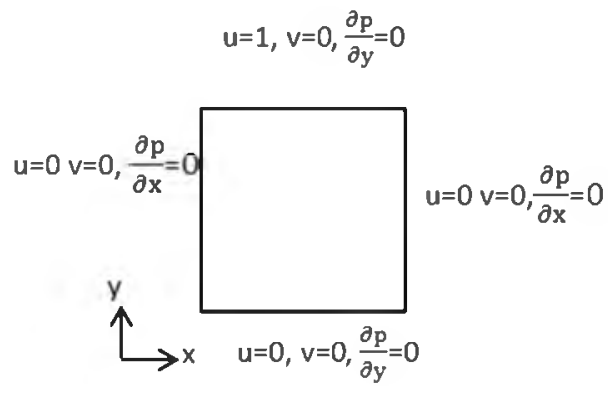

Gambar 1. Domain danSyarat Batas

\section{PersamaanAtur}

Persamaan atur kasus Lid Driven Cavity terdiri dari persamaan kontinyuitas dan persamaan momentum yang merupakan persamaan Navier-Stokes. Untuk kasus tak tunak (unsteady) dan incompresible 2-D dimana tegangan permukaan diabaikan dan viskositas fluida dianggap sama, persamaan atur menjadi :

$$
\begin{aligned}
& \frac{\partial u}{\partial x}+\frac{\partial v}{\partial y}=0 \\
& \frac{\partial u}{\partial t}+u \frac{\partial u}{\partial x}+v \frac{\partial u}{\partial y}=-\frac{\partial p}{\partial x}+\frac{1}{\operatorname{Re}}\left(\frac{\partial^{2} u}{\partial x^{2}}+\frac{\partial^{2} u}{\partial y^{2}}\right) \\
& \frac{\partial v}{\partial t}+u \frac{\partial v}{\partial x}+v \frac{\partial v}{\partial y}=-\frac{\partial p}{\partial y}+\frac{1}{\operatorname{Re}}\left(\frac{\partial^{2} v}{\partial x^{2}}+\frac{\partial^{2} v}{\partial y^{2}}\right)
\end{aligned}
$$

Dimana $\mathrm{u}$ dan $\mathrm{v}$ adalah komponen kecepatanarah $-\mathrm{x}$ dan $-\mathrm{y}, \mathrm{p}$ adalah suku tekanan dan Re adalah bilangan Reynolds

\section{Metodologi}

Prosedur penyelesaian persamaan Navier-Stokes menggunakan metode Pressure Correction. Langkah pertama persamaan momentum diselesaikan dengan mengabaikan suku tekanan, ditunjukkan berikut :

i). Persamaan $\mathrm{x}$ - momentum :

$\frac{\partial u}{\partial t}+u \frac{\partial u}{\partial x}+v \frac{\partial u}{\partial y}=-\frac{\partial p}{\partial x}+\frac{1}{\operatorname{Re}}\left(\frac{\partial^{2} u}{\partial x^{2}}+\frac{\partial^{2} u}{\partial y^{2}}\right)$

Suku tekanan diabaikan :

$$
\begin{gathered}
\frac{\partial u}{\partial t}+u \frac{\partial u}{\partial x}+v \frac{\partial u}{\partial y}=\frac{1}{\operatorname{Re}}\left(\frac{\partial^{2} u}{\partial x^{2}}+\frac{\partial^{2} u}{\partial y^{2}}\right) \\
\frac{\partial u}{\partial t}=\frac{u_{i, j}^{n+1}-u_{i, j}^{n}}{\Delta t} \\
u_{i, j}+\Delta t\left[\left(u \frac{\partial u}{\partial x}+v \frac{\partial u}{\partial y}\right)-\frac{1}{R e}\left(\frac{\partial^{2} u}{\partial x^{2}}-\frac{\partial^{2} u}{\partial y^{2}}\right)\right]=u_{i, j}^{n}
\end{gathered}
$$

ii). y-Momentum :

$\frac{\partial \mathrm{v}}{\partial \mathrm{t}}+\mathrm{u} \frac{\partial \mathrm{v}}{\partial \mathrm{x}}+\mathrm{v} \frac{\partial \mathrm{v}}{\partial \mathrm{y}}=-\frac{\partial \mathrm{p}}{\partial \mathrm{y}}+\frac{1}{\operatorname{Re}}\left(\frac{\partial^{2} \mathrm{v}}{\partial \mathrm{x}^{2}}+\frac{\partial^{2} \mathrm{v}}{\partial \mathrm{y}^{2}}\right)$

Suku tekanan diabaikan

$$
\begin{aligned}
& : \frac{\partial v}{\partial t}+u \frac{\partial v}{\partial x}+v \frac{\partial v}{\partial y}=\frac{1}{R e}\left(\frac{\partial^{2} v}{\partial x^{2}}+\frac{\partial^{2} v}{\partial y^{2}}\right) \\
& \frac{\partial v}{\partial t}=\frac{v_{i, j}^{n+1}-v_{i, j}^{n}}{\Delta t} \\
& \bar{v}_{i, j}+\Delta t\left[\left(v \frac{\partial \bar{v}}{\partial x}+v \frac{\partial \bar{v}}{\partial y}\right)-\frac{1}{R e}\left(\frac{\partial^{2} \bar{v}}{\partial x^{2}}+\frac{\partial^{2} \bar{v}}{\partial y^{2}}\right)\right] \\
& =v_{i, j}^{n}
\end{aligned}
$$

Nilai $\overline{\mathrm{u}}$ dan $\mathrm{v}^{-}$merupakan kecepatan tingkat menengah tanpa tekanan yang tidak memenuhi persamaan kontinyuitas, sedangkan $\mathbf{n}$ menunjukkan tingkat waktu. Langkah selanjutnya menghitung tekanan $\mathrm{p}^{\mathrm{n}+1}$ dengan persamaan Poisson. Persamaan 
ini diperoleh dari kombinasi antara persamaan momentum dan persamaan kontinyuitas.Persamaan Poissonditunjukkan,

$\left(\frac{\partial^{2} \mathrm{p}}{\partial \mathrm{x}^{2}}+\frac{\partial^{2} \mathrm{p}}{\partial \mathrm{y}^{2}}\right)^{\mathrm{n}+1}=\Delta \mathrm{t}\left(\frac{\partial \overline{\mathrm{u}}}{\partial \mathrm{x}}+\frac{\partial \overline{\mathrm{v}}}{\partial \mathrm{y}}\right)$

Setelahsukutekanan $\mathrm{P}_{\mathrm{i}, \mathrm{j}}^{\mathrm{n}+1}$ diperoleh maka digunakan

untukmenghitungkecepatansesungguhnyayai $\operatorname{tuu}_{\mathrm{i}, \mathrm{j}}^{\mathrm{n}+1}$ dan $v_{\mathrm{i}, \mathrm{j}}^{\mathrm{n}+1}$

$\frac{1}{\Delta \mathrm{t}}\left(\mathrm{u}^{\mathrm{n}+1}-\overline{\mathrm{u}}\right)=-\frac{\partial \mathrm{p}^{\mathrm{n}+1}}{\partial \mathrm{x}}$, maka $\mathrm{u}^{\mathrm{n}+1}-\overline{\mathrm{u}}=$ $-\Delta \mathrm{t} \frac{\partial \mathrm{p} 1}{\partial \mathrm{x} \Delta \mathrm{t}}\left(\mathrm{v}^{\mathrm{n}+1}-\mathrm{v}\right)=-\frac{\partial \mathrm{p}^{\mathrm{n}+1}}{\partial \mathrm{y}}$ maka

$\mathrm{v}^{\mathrm{n}+1}-\mathrm{v}=-\Delta \mathrm{t} \frac{\partial \mathrm{p}}{\partial \mathrm{y}}$

5. DiskritisasiPersamaanAtur

Dalam persamaan differensial terdapat sukusuku yang mengandung turunan. Suku-suku ini diubah menjadi suatu persamaan yang mengandung operasi aritmetik. Proses pengubahan disebut dengan diskritisasi spatial. Diskritisasi dalam permasalahan ini menggunakan Staggered Grid skema implisit yang dianggap lebih stabil dibanding eksplisit. Tekanan $p$ diasumsikan berada ditengah volume atur, komponen kecepatan horizontal (u) terletak di tengah sisi kanan dan kiri volume atur. Sedangkan komponen kecepatan vertikal (v) pada tengah sisi atas dan bawah volume atur. Penyelesaian diperlukan tridiagonal matrik dengan skema ADI yang dipisahkan dalam beberapa matrik scalar tridiagonal. Di formulasikan algoritma skema implicit terpisah diharapkan perhitungan komputasi lebih efisien.

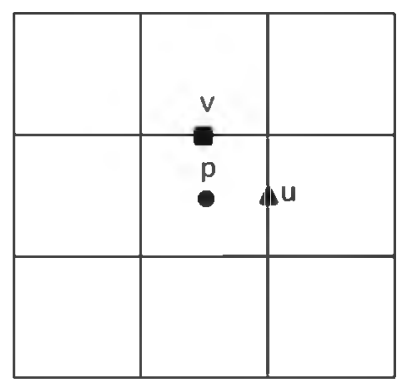

Gambar 2.Konfigurasivariable kecepatandan variable tekananpada grid staggered.

Diskritisasi x-momentum :

$a_{i} u_{i-1, j}^{n+1}+b_{i} u_{i, j}^{n+1}+c_{i} u_{i+1, j}^{n+1}=d_{i}$ dengan :

$$
\begin{aligned}
\mathrm{a}_{\mathrm{i}}= & -\frac{\mathrm{UL}}{2 \Delta \mathrm{x}}-\frac{1}{\operatorname{Re}(\Delta \mathrm{x})^{2}} \\
\mathrm{~b}_{\mathrm{i}}= & \frac{1}{\Delta \mathrm{t}}+\frac{\mathrm{UR}-\mathrm{UL}}{2 \Delta \mathrm{x}}+\frac{\mathrm{VT}-\mathrm{VB}}{2 \Delta \mathrm{y}}+\frac{2}{\operatorname{Re}}\left(\frac{1}{(\Delta \mathrm{x})^{2}}+\frac{1}{(\Delta \mathrm{y})^{2}}\right) \\
\mathrm{c}_{\mathrm{i}}= & \frac{\mathrm{UR}}{2 \Delta \mathrm{x}}-\frac{1}{\operatorname{Re}(\Delta \mathrm{x})^{2}} \\
\mathrm{~d}_{\mathrm{i}}= & \frac{\mathrm{u}_{\mathrm{i}, \mathrm{j}}}{\Delta \mathrm{t}}-\frac{\mathrm{VT}}{2 \Delta \mathrm{y}} \mathrm{u}_{\mathrm{i}, \mathrm{j}+1}^{\mathrm{n}}+\frac{\mathrm{VB}}{2 \Delta \mathrm{y}} \mathrm{u}_{\mathrm{i}, \mathrm{j}-1}^{\mathrm{n}}+ \\
& \frac{1}{\operatorname{Re}}\left(\frac{\mathrm{u}_{\mathrm{i}, \mathrm{j}-1}+\mathrm{u}_{\mathrm{i}, \mathrm{j}+1}^{\mathrm{n}}}{(\Delta \mathrm{y})^{2}}\right)
\end{aligned}
$$

Diskritisasi y-momentum :

$a_{i} v_{i-1, j}^{n+1}+b_{i} v_{i, j}^{n+1}+c_{i} v_{i+1, j}^{n+1}=d_{i}$

dengan :

$$
\begin{aligned}
& \mathrm{a}_{\mathrm{i}}=-\frac{\mathrm{UL}}{2 \Delta \mathrm{x}}-\frac{1}{\operatorname{Re}(\Delta \mathrm{x})^{2}} \\
& \mathrm{~b}_{\mathrm{i}}=\frac{1}{\Delta \mathrm{t}}+\frac{\mathrm{UR}-\mathrm{UL}}{2 \Delta \mathrm{x}}+\frac{\mathrm{VT}-\mathrm{VB}}{2 \Delta \mathrm{y}}+\frac{2}{\mathrm{Re}}\left(\frac{1}{(\Delta \mathrm{x})^{2}}+\frac{1}{(\Delta \mathrm{y})^{2}}\right) \\
& \mathrm{c}_{\mathrm{i}}=\frac{\mathrm{UR}}{2 \Delta \mathrm{x}}-\frac{1}{\operatorname{Re}(\Delta \mathrm{x})^{2}} \\
& \mathrm{~d}_{\mathrm{i}}=\frac{\mathrm{u}_{\mathrm{i}, \mathrm{j}}^{\mathrm{n}}}{\Delta \mathrm{t}}-\frac{\mathrm{VT}}{2 \Delta \mathrm{y}} \mathrm{v}_{\mathrm{i}, \mathrm{j}+1}^{\mathrm{n}}+\frac{\mathrm{VB}}{2 \Delta \mathrm{y}} \mathrm{v}_{\mathrm{i}, \mathrm{j}-1}^{\mathrm{n}}+ \\
& \frac{1}{\operatorname{Re}}\left(\frac{v_{i, j-1}^{n}+u_{i, j+1}^{n}}{(\Delta y)^{2}}\right) \\
& \mathrm{UR}=\frac{\mathrm{u}_{\mathrm{i}, \mathrm{j}}^{\mathrm{n}}+\mathrm{u}_{\mathrm{i}+1, \mathrm{j}}^{\mathrm{n}}}{2} \quad ; \quad \mathrm{UL}=\frac{\mathrm{u}_{\mathrm{i}, \mathrm{j}}^{\mathrm{n}}+\mathrm{u}_{\mathrm{i}-1, \mathrm{j}}^{\mathrm{n}}}{2} \quad ; \\
& \mathrm{VT}=\frac{\left(v_{\mathrm{i}, \mathrm{j}}^{\mathrm{n}}+\mathrm{v}_{\mathrm{i}+1, \mathrm{j}}^{\mathrm{n}}\right)}{2} ; \mathrm{VB}=\frac{\left(\mathrm{v}_{\mathrm{i}, \mathrm{j}-1}^{\mathrm{n}}+\mathrm{v}_{\mathrm{i}+1, \mathrm{j}-1}^{\mathrm{n}}\right)}{2}
\end{aligned}
$$

Metode Pressure Correction :

$u_{i, j}^{n+1}=\bar{u}-\Delta t \frac{\partial p}{\partial x}$
$v_{i, j}^{n+1}=\bar{v}-\Delta t \frac{\partial p}{\partial y}$

$\left(\frac{\partial^{2} \mathrm{p}}{\partial \mathrm{x}^{2}}+\frac{\partial^{2} \mathrm{p}}{\partial \mathrm{y}^{2}}\right)^{n+1}=\Delta \mathrm{t}\left(\frac{\partial \overline{\bar{i}}}{\partial \mathrm{x}}+\frac{\partial \overline{\mathrm{v}}}{\partial \mathrm{y}}\right)$

$\mathrm{p}_{\mathrm{i}-1, \mathrm{j}}^{\mathrm{k}+1}-2\left(1+\left(\frac{\Delta \mathrm{x}}{\Delta \mathrm{y}}\right)^{2}\right) \mathrm{p}_{\mathrm{i}, \mathrm{j}}^{\mathrm{k}+1}+\mathrm{p}_{\mathrm{i}+1, \mathrm{j}}^{\mathrm{k}+1}=$

$-\left(\frac{\Delta x}{\Delta y}\right)^{2}\left(p_{i, j-1}^{k+1}+p_{i, j+1}^{k}\right)+\frac{(\Delta x)^{2}}{\Delta t}\left(\frac{u_{i, j}-u_{i-1, j}}{\Delta x}+\right.$

$\left.\frac{v_{i, j}-v_{i, j-1}}{\Delta y}\right)($

Diskritisasikoreksikecepatan

$$
\begin{aligned}
& \mathrm{u}^{\mathrm{n}+1}=\overline{\mathrm{u}}-\frac{\partial \mathrm{p}}{\partial \mathrm{x}} \\
& \mathrm{v}^{\mathrm{n}+1}=\overline{\mathrm{v}}-\frac{\partial \mathrm{p}}{\partial \mathrm{y}}
\end{aligned}
$$


6. Hasil Dan Pembahasan

Gambar 1 menunjukkan domain dan syarat batas kasus yang diselesaikan dimana nilai komponen kecepatan horisontal (u) pada batas atas adalah satu. Kasus diselesaikan pada bilangan Reynolds antara 100-10000. Validasi hasil perhitungan dilakukan dengan membandingkan kecepatan u pada $\mathrm{x}=0.5$ untuk nilai bilangan Reynolds 100dengan hasil perhitungan dari Ghia (1982). Hasil perbandingan menunjukkan kesesuaian yang baik, sehingga dapat disimpulkan bahwa metode yang digunakan memiliki akurasi yang baik untuk menyelesaikan kasus aliran fluida tak mampat.

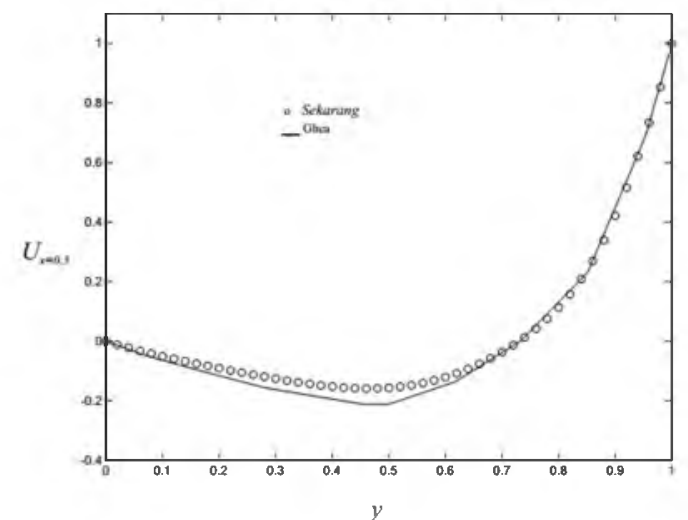

Gambar 3.Perbandingan kecepatan horizontal $\mathrm{u}$ pada $\mathrm{x}=0.5$ dengan penelitian Ghea (1982).

Gambar 4. Menunjukkan vektor kecepatan untuk bilangan Rreynolds 100 , 400,1000 dan 10000. Pada Re rendah (Re $=100$ dan 400) hanya terlihat vortek utama di tengah, sedangkan pada $\mathrm{Re}$ tinggi $(\mathrm{Re}=$ 1000 dan 10.000) selain vorteks utama juga terbentuk vorteks sekunder pada pojok kiri bawah dan kanan bawah.

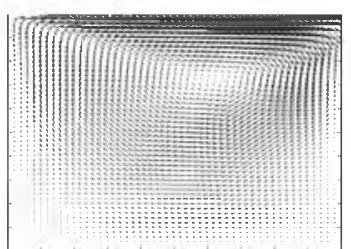

$$
\operatorname{Re}=100
$$

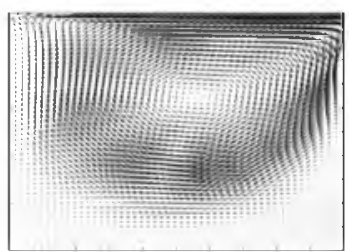

$\operatorname{Re}=1000$

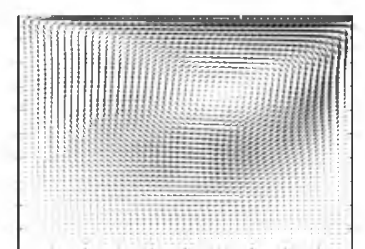

$\mathrm{Re}=400$

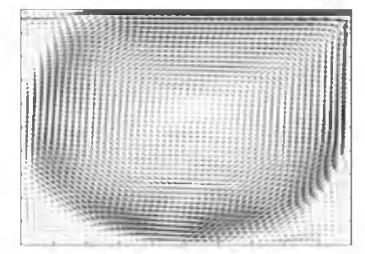

$\operatorname{Re}=10000$
Gambar 4. Vektor kecepatan untuk nila $\operatorname{Re}=$ $100,400,1000$ dan 10000 .

7. Kesimpulan

Persoalan aliran fluida tak mampat (incompressible) dapat diselesaikan dengan algoritma Pressure Correction. Algoritma tersebut untuk menghitung persamaan Navier-Stokes tanpa menggunakan suku tekanan (pressure-term). Sehingga diperoleh kecepatan tingkat menengah u dan v. Suku tekanan dihitung menggunakan persamaan Poisson, sedangkan kecepatan sesungguhnya $\quad \mathrm{u}^{\mathrm{n}+1}$ dan $\quad \mathrm{v}^{\mathrm{n}+1}$ dihitung berdasarkan tingkat kecepatan menengah $\mathbf{u}$ dan v yang dikoreksi dengan suku tekanan.

Hasil penyelesaian kasus driven cavity menunjukkan adanya kesesuaian yang baik dibandingkan dengan penelitian Ghia, 1982; Ertruk, 2005. Metode penyelesaian metodetak mampat (incompressible) menggunakan metodePressure Correction mampu menyelesaiakan Lid Driven Cavity sampai bilangan Reynold $\mathrm{Re}=10^{4}$.

\section{DAFTARPUSTAKA}

[1] Ertruk.E, Corke. T. C., Gokqol. C., 2005, Numerical Solutions of 2-D Steady Incomprssible Driven Cavity Flow at High Reynolds Numbers, Int. J. for Numerical Methods in Fluids.

[2] Ghia. U, Shin. C.T., 1982, High-Re Solutions For Incomprssible Flow Using TheNavier-Stokes Equations and Method,Journal of Computational Physics, 48 (1982), p387-411. 
[3] Marchi CH, Suero R, Araki L. K., 2009, The Lid-Driven Square Cavity Flow: Numerical Solution with a 1024 $x 1024$ Grid, J. Journal of The Braz. Soc.of Mech. Sci. \& Eng., Volume 31.

[4] Tamer AbdelMigid..A., Khalid. M.S., 2017, Revisiting the Lid-Driven Caviity Flow Problem:Review and New Steady State Benchmarking Results Using GPU Accelerated Code, Alexandria Eng. J., 56, p123125.

[5] Lemee. T, Kaperski. G, 2015, Multiple Stable Solutions in the 2D Symmetrical two-sided Square LidDriven Cavity, Computer and Fluids, 119, p204-212.

[6] Li Zhenquan, Wood R., 2015, Journal Analysis of an Adaptive Mesh Refinerment Method Using Benchmarks of $2 D$ Steady Incompressible Lid-Driven Cavity and Coarser Meshes, J. Of Computational and Applied Mathematics, 275, p262271.
[7] Kao Po-Hao, Yang. R, 2007, $A$ Segregated-implicit Scheme for Solving the Incompressible NavierStokes Equations, Computer and Fluid, 36, p1159-1161ving

[8] Joel Chorin. A, 1997, A Numerical Method for Solving Incompressible Viscous Flow Problems, J. Of Computational Phisics, 135, p118125.

[9] Peskin, C.S., 1985, A Random-Walk Interpretation of the Incompressible Navier-Stokes Equations. Pure and Applied Mathematics, vol. XXXVIII (1985), p. 845-852.

[10] Richtmyer, R.D., Morton, K.W., Difference Methods for Initial Value Problems (Interscience, New York, 1967).

[11] Tryggvason, G., 2012, A Fronttracking/Finite-Volume Navier-Stokes Solver for Direct Numerical Simulations of Multiphase Flows.

[12] Tuakia, F., 2008. Dasar-dasar CFD Menggunakan Fluent. Informatika Bandung, 